\title{
La calle es un lugar -Escenas de interacción entre varones homosexuales y agentes policiales durante la década de 1980 en Córdoba (Argentina)*
}

\author{
Gustavo Blázquez** \\ Ana Laura Reches Peressotti***
}

\section{Resumen}

En Argentina, durante la década de 1980, varones homosexuales que frecuentaban determinados espacios nocturnos se arriesgaban a diversas maneras de persecución por parte de agentes policiales. En este artículo analizamos, a partir de la realización de una serie de entrevistas en profundidad, interacciones desarrolladas entre dichos sujetos y agentes de la Policía de la Provincia de Córdoba en el escenario social de la calle. Esos jóvenes coprotagonizaban "escenas de peligro" donde el diferencial de poder entre los participantes colocaba en riesgo la existencia social y física de quienes ocupaban la posición subordinada. El estudio de esas escenas permite describir tácticas utilizadas por los y las entrevistadas y, al mismo tiempo, reconocer cómo las mismas variaron en función de los diferenciales de poder entre los involucrados.

Palabras clave: Homosexualidad, Peligro, Poder, Performance, Tácticas.

* Recibido el 01 de febrero de 2017, aceptado el 14 de agosto de 2017.

** Docente e Investigador de la Universidad Nacional de Córdoba, IDH/CONICET, Córdoba, Argentina. gustavoblazquez3@hotmail.com

*** Doctoranda en Ciencias Antropológicas de la Universidad Nacional de Córdoba, CIFFyH/CONICET, Córdoba, Argentina. laureches@hotmail.com 
The Street is a Place - Scenes of Interaction between Homosexual Men and The Police During The Decade of 1980 in Córdoba (Argentina)

\begin{abstract}
In Argentina, during the 1980s, homosexual men who frequented certain night areas risked themselves to various ways of persecution by police officers. In this article we analyze, from the completion of a series of in-depth interviews, interactions developed between the subjects and agents of the police of the province of Cordoba, in the social scene of thestreet. These young men co-starred "dangerscenes" where the differential of power between the participants placed at risk the social and physical existence of those who were in the subordinate position. The study of these scenes allows to describe the tactics used by the interviewees and, at the same time, to recognize how they varied according to the power differentials between those involved.
\end{abstract}

Keywords: Homosexuality, Danger, Power, Performance, Tactics. 
La calle es su lugar ella sabe bien

no va a volver atrás ni por uno, ni por veinte ni por cien (G.I.T., "La calle es su lugar")

articular históricamente el pasado significa apoderarse de un recuerdo tal como éste relampaguea en un instante de peligro (Walter Benjamin, "Tesis de filosofía de la historia")

Este artículo surge de una investigación más amplia que se detiene en las formas de sociabilidad de jóvenes varones homosexuales durante la década de 1980 en la ciudad de Córdoba, Argentina. En tiempos del Terrorismo de Estado y durante los primeros años del gobierno de Raúl Alfonsín, frecuentar ciertos establecimientos comerciales nocturnos, caminar por algunos espacios públicos, vestir de determinados modos, exhibir peinados "raros", expresar determinados afectos, eran prácticas que implicaban grandes riesgos vinculados tanto con reiteradas formas de persecución policial (detenciones individuales y razias colectivas) como con la condena social y el oprobio público. Sin embargo, animados por el deseo y dispuestos a vivir la vida, esos jóvenes tomaron la calle y al encontrarse con las fuerzas policiales protagonizaron, lo que proponemos llamar, "escenas de peligro". ${ }^{1}$

Esas "escenas de peligro" pueden describirse como "situaciones sociales" (Gluckman, 2003) en las cuales tanto los entrevistados como quienes los hostigaban disputaban un asunto de interés mutuo y libraban una batalla en pos de redefinir,

1 A lo largo de este trabajo utilizaremos comillas tanto para relativizar algunos términos como para referirnos a conceptos o citas bibliográficas. Utilizaremos la tipografía itálica para señalar términos que emergen de las entrevistas o de las fuentes documentales. Los corchetes serán empleados para realizar aclaraciones de los autores en las citas de las entrevistas. 
actualizar, transformar o bien conservar una moral sexual, así como quiénes podían aparecer en el espacio público. Pero el diferencial de poder entre los participantes de tales escenas colocaba en riesgo la existencia social y física de quienes ocupaban una posición subordinada. Esos encontronazos, más o menos violentos, se daban entre sujetos en riesgo por sus prácticas eróticas y el "brazo armado" del Estado, destinado a reprimirlos. En ellos se puede observar la tradición de los oprimidos capaz de, como sostiene Walter Benjamin (1995), enseñarnos que el "estado de excepción" en que vivimos es la regla.

En tanto conductas restauradas (Schechner, 2000), esas escenas estaban organizadas por guiones y suponían distintas prácticas que, según analizamos, se aprendían y ensayaban con los pares y en soledad. Los vívidos relatos acerca de esas performances son parte de un "repertorio" (Taylor, 2011) que cuenta cómo estructuraban las interacciones y cuáles eran las tácticas puestas en juego por los oprimidos para continuar viviendo. ${ }^{2}$ En cada relato, o en cada acto de contar, como plantea la "Antropología de la experiencia" (Bruner y Turner, 1986), los sujetos interpretaban corporalmente $y$ daban sentido a sus experiencias vitales, mientras renovaban y transformaban las imágenes y expresiones sobre esas "escenas de peligro".

Esos relatos permitirán describir y analizar las interacciones entre nuestros interlocutores y agentes policiales, desarrolladas en la vía pública. ${ }^{3}$ A partir de esas historias (re)vividas nos

2 Según Diana Taylor los materiales de estudio pueden estar organizados como un "archivo" en documentos, textos, estadísticas o como un "repertorio" que consiste en la memoria corporal que circula a través de performances, gestos, narración oral, movimiento, danza, canto. Estos repertorios forman parte de la transmisión de esas experiencias en tanto que "La memoria corporal, siempre en vivo, no puede reproducirse en el archivo" (Taylor, 2011:14).

${ }^{3}$ Esos encuentros callejeros se diferenciaban de otro conjunto de interacciones desarrolladas en bares, discotecas y fiestas privadas. En esos espacios, definidos por los sujetos como refugios, se reunía un auditorio segregado y exclusivo de iguales cuyo ingreso y permanencia estaba mediado por la participación en una red de conocidos. En esos lugares, más relajados, se desarrollaban performance de género asociadas a la feminidad y el homoerotismo que no podían montarse 
preguntamos: ¿Cómo esos jóvenes varones buscaban "definir la situación" (Goffman, 1971:15) en esas "escenas de peligro"? ¿Cuáles fueron las tácticas y lógicas relacionales imbricadas en sus acciones? ¿Cómo se transformaron, a lo largo de la década de 1980, los desequilibrios de poder entre los protagonistas? También se podrán conocer algunas de las técnicas usadas por quienes encarnaban la represión policial de la homosexualidad en los años que van desde el final de la última dictadura argentina a la "primavera alfonsinista".

En el desarrollo de este texto nos valemos de una serie de entrevistas en profundidad, biográficamente centradas, realizadas a 30 (treinta) personas auto-reconocidas como homosexuales o travestis. El recorte metodológico incluyó a individuos reunidos a partir de la técnica de bola de nieve, pertenecientes a sectores de ingresos medios, residentes en la ciudad de Córdoba durante la década de 1980 y que, al momento de las entrevistas, tenían entre 45 y 70 años. En esas conversaciones buscamos articular las trayectorias individuales y grupales de los sujetos con sus formas y circuitos de divertimento así como especificar los modos de encontrarse y reconocerse con sus pares durante el período en cuestión. Paralelamente, indagamos sobre sus prácticas frente al acoso homo-transfóbico en sus mundos laborales y en su vida familiar y la persecución policial en distintos espacios sociales. A lo largo de este escrito señalaremos la edad de nuestros interlocutores en el momento de la entrevista, aunque se emplearán seudónimos para preservar el anonimato de los sujetos.

\section{La década de 1980 en Argentina y los estudios sobre las homosexualidades masculinas}

en otros escenarios. En los refugios la mirada corrupta de la policía penetraba bajo la lógica de la coima que aseguraba la (dis)continuidad del emprendimiento comercial. Los agentes policiales podían llegar en cualquier momento, que no era cualquier momento, y desbaratar la fiesta. En ese contexto, y reforzando el carácter de refugio, los sujetos construían un saber que anticipaba la llegada de los agentes policiales al mismo tiempo que instalaban dispositivos que avisaban el peligro que se avecinaba (Reches, 2014). 
En Argentina la última dictadura militar, autodenominada "Proceso de Reorganización Nacional", tuvo fuertes intenciones (re)fundacionales (Quiroga, 2004). Entre sus principales objetivos estaba (re)crear un nuevo orden (social-político-económico) que preveía la "desaparición" de quienes participaban en organizaciones armadas o subversivas. Pero, dado que la sospecha de subversión podía recaer sobre (casi) cualquier ciudadano, el miedo y el terror se propagó de modo generalizado (Calveiro, 2005).

Esos sentimientos eran simultáneamente reafirmados por las políticas de Terrorismo de Estado, que pusieron al aparato estatal al servicio de esas acciones, organizadas en un plan sistemático de tortura, desaparición, exterminio, robo, saqueo económico y apropiación de niños. Artistas de vanguardia, del campo popular o asociados con el rock, consumidores de sustancias psicoactivas ilegales, delincuentes comunes, prostitutas, entre otros y otras integraban poblaciones sino subversivas, al menos peligrosas $y$ dañinas, que también resultaron objeto de políticas represivas. Homosexuales y travestis fueron igualmente perseguidos por la fuerza pública durante esos años (Perlongher, 2008). En ese contexto, algunos "jóvenes" encontraron "intersticios de resistencia" que acompañaron y contribuyeron a la crisis de la dictadura militar, ya sea en el campo de las artes plásticas (González, 2012), en el de la música (Bruno, 2014), en el "under" porteño (Lucena, 2013), en el teatro (Longoni, 2014).

Entre los años setenta y la segunda mitad de la década de 1980, la homosexualidad permanecía en la clandestinidad, experiencia que -según Meccia (2006)- promovió una identidad y un colectivo homosexual. Rapisardi \& Modarelli (2001) muestran cómo algunas locas porteñas durante la última dictadura militar transitaban saunas, baños públicos, bares y fiestas. En un contexto hostil, los sujetos delinearon algunos "mecanismos de defensa" 
frente a la violencia estatal, que asumía la forma de coimas, detenciones, abusos (Rapisardi \& Modarelli, 2001:97). ${ }^{4}$

A inicios de la década de 1980, las políticas dictatoriales condujeron a una crisis generalizada. Las violaciones a los derechos humanos comenzaron a resonar con mayor intensidad en el exterior, la depresión económica (con altos niveles de inflación, desindustrialización, deuda pública) y los conflictos al interior de las Fuerzas Armadas (con discrepancias entre sus distintos cuerpos), debilitó a la cúpula gobernante. En consonancia con la atmósfera bélica y militarista de aquellos años, el dictador Leopoldo Galtieri embarcó al país en el intento por recuperar las Islas Malvinas, territorio administrado por el Reino Unido y cuya soberanía era reclamada por Argentina desde la tercera década del siglo XIX. La derrota de una guerra lapidaria confirmó el trazo que marcaba la decadencia de la dictadura, y con ello otro rumbo político se hizo posible para el país: el llamado a elecciones democráticas.

4 Bazán (2006) señala cómo en Buenos Aires el edicto policial $2^{\circ} \mathrm{H}$ avalaba la facultad de la policía para aplicar penas hacia la homosexualidad en el caso que las detenciones ocurrieran en la vía pública. Si las mismas se llevaban a cabo en espacios cerrados, las contravenciones aplicadas eran ebriedad o escándalo (Bazán, 2006:358). El Código de Faltas vigente en la Provincia de Córdoba (ley $\mathrm{n}^{\circ}$ 6392) habilitaba la detención de varones homosexuales por motivos semejantes. Este Código se sancionó y promulgó de modo definitivo el 17 de abril de 1980 y reguló las faltas cometidas en el territorio de la Provincia de Córdoba hasta 1994, cuando fue derogado por la Ley n 8431 . El Código de Faltas vigente durante la década de 1980 consta de tres partes, que en su conjunto buscan la unificación del régimen de faltas en todo el ámbito provincial. La primera parte expone una serie de disposiciones generales ordenadas en doce artículos, que regulan cuestiones tales como el ámbito de aplicación de la ley, culpabilidad y causas de imputabilidad, cumplimiento de la pena, pago y términos de las multas, agravantes, etc. La segunda parte se titula "de las faltas y sus sanciones" y se encuentra organizada en cinco títulos: "I. Desórdenes y escándalos públicos", "II. Decencia pública", "III. Seguridad pública", "IV. Seguridad de la propiedad" y " $V$. Caza y pesca". Cada uno de estos apartados contiene un conjunto de reglamentaciones, enumeradas en artículos. La última parte se denomina "normas de procedimiento" y explicita el modo en que debía proceder, administrativamente, la Policía de la Provincia de Córdoba (Reches, 2014). 
En 1982, la democracia se constituía en una ilusión que luego se materializaría en una salida electoral concreta cuando, en octubre de 1983, se efectivizaron los sufragios en las distintas provincias argentinas. La Unión Cívica Radical obtuvo la mayoría de las gobernaciones del país y, por primera vez, vencía al peronismo en las presidenciales. Raúl Alfonsín ocupó el ejecutivo nacional. En Córdoba, Eduardo Angeloz fue electo gobernador y detentó ese cargo por doce años (1983-1995).

Durante los primeros años del gobierno alfonsinista se impulsaron juicios que condenaron a los máximos jerarcas de la dictadura. También se intentó implementar una reforma educativa, un plan de democratización de la cultura, y se experimentó una primavera democrática (Cavarozzi, 2006; Romero, 2001). En la década de 1980, se produjo una redefinición de las morales sexuales o "destape". La sanción de la Ley de Divorcio, a su vez, articuló cuestiones referidas a derechos, ciudadanía y relaciones interpersonales (Pecheny, 2010:89) y la expansión de la epidemia de sida, sumada a la organización de grupos como la Comunidad Homosexual Argentina (CHA) (Jauregui, 1987; Bellucci, 2010) promovió la aparición de la sexualidad como un tema de la agenda política democrática.

Algunas narrativas de varones homosexuales adultos y adultos mayores analizadas por Meccia (2016) muestran transformaciones en la homosexualidad y la sociabilidad homosexual en la ciudad de Buenos Aires entre 1983 y 2013. Desde la reapertura democrática, un conjunto de cambios habrían transformado dichas experiencias sociales, que se fueron redefiniendo a medida que se democratizaban las relaciones políticas (Meccia, 2006, 2011, 2016).

Por diferentes caminos la homosexualidad abandonaba la clandestinidad. Distintos personajes y temáticas fueron asomándose en la escena pública porteña (Bazán, 2006) y hacía su comingout en la cinematografía (Blázquez, 2015), en la organización de una "noche gay" y la formación de un "pinkmarket" (Reches, 2014), en la formación de grupos que luchaban por los derechos de los homosexuales (Bellucci, 2010). 
Los entrevistados recordaban los años asociados a la "primavera alfonsinista" con alegría y como un momento de libertad y experimentación. Pero también relataban continuidades en lo que refiere a constantes formas de represión policial que parecieron incrementarse con la llegada de la democracia. Resulta preciso aclarar que, pese a que el gobernador Angeloz se enunció como ajeno a la violencia política (Servetto y González, 2014), durante su gestión en el ejecutivo provincial mantuvo en actividad a un grupo de policías -muchos de los cuales ocupaban las posiciones de mando en la jerarquía policial- que participaron activamente en el ex centro de tortura que funcionaba en el Departamento de Inteligencia de la Policía de la Provincia de Córdoba (D2) y en otras acciones del terrorismo de estado.

\section{Escenas de peligro}

Con el objetivo de profundizar el conocimiento de los procesos del devenir varón homosexual durante la década de 1980 en una relevante ciudad del interior argentino proponemos analizar interacciones, poco estudiadas en los trabajos citados, como aquellas que se daban entre los entrevistados y fuerzas policiales en el escenario social de la calle..$^{5} \mathrm{El}$ análisis de esas escenas permitirá conocer algunas de las tácticas utilizadas por los participantes para (no) decir(se) y hacer(se) un sujeto homosexual

${ }^{5}$ Para pensar la vía pública en relación a nuestro objeto de estudio contamos con el trabajo de Sívori que analiza el circuito de sociabilidad homosexual en Rosario a inicios de la década de 1990. Disponemos de un artículo del autor donde llama la atención sobre la presencia estatal en el uso del espacio público. Específicamente se focalizó en relatos sobre la policía en la vida cotidiana de los rosarinos que habitaban aquel circuito de yiro. Según Sívori, esos territorios se conformaban delimitando áreas en las cuales la actuación policial (individuos identificados como canas por los sujetos) objetivaba la presencia estatal mediante detenciones, acoso y extorsiones que imprimían un carácter moralizador a la práctica del levante callejero. El autor describe cómo los sujetos construían la figura de la policía como potencial predadora económica y sexual, dada su ambigua y ambivalente participación en ese territorio homoerótico (Sívori, 2004). 
y reconocer cómo esas tácticas variaron en función de los diferenciales de poder entre los involucrados.

\section{Yo no soy}

Héctor tenía 54 años cuando lo entrevistamos en 2012. Durante la década de 1980, junto a varios amigos formaron un grupo que organizaba espectáculos musicales, teatrales y coreográficos actuando personajes como transformistas. Una tarde de primavera nos recibió en su casa en un barrio cercano al centro de la ciudad de Córdoba, donde mantuvimos una larga conversación. Allí nos relató lo que le sucedió una noche, a principios de los años 1980, luego de una salida a un bar con su amigo Jorge:

Veníamos caminando [con Jorge], y de pronto se nos cruzan dos tipos de civil que nos separan. Entonces nos dicen: "documentos". Les damos los documentos, "¿de dónde vienen?", "de tal lado". Les dijimos la verdad porque era un bar común, como si te sentaras ahora en cualquier bar. Entonces agarra y me dice: "iusted es homosexual!", "no", "sí iusted es homosexual!", "no, no, no y no" y el otro [agente policial] lo estaba charlando a Jorge. Y el pelotudo le dice que sí. Entonces agarra el otro y me dice: "¿cómo tu amigo dice que sí?", "será él, yo no", "pero él dice que vos sos", "él puede decir cualquier cosa, pero yo no soy. Yo no soy". Había que negarlo a muerte, ¿̇me entendés? Porque yo sé que quedabas asentado.

Este relato hace eco en las historias de otros entrevistados. Una mañana de abril de 2011 nos reunimos con Armando (63 años) en la dependencia municipal donde trabaja. Allí nos contó que, pese a que nada feo ni nada malo le sucedió en sus interrelaciones con la policía, sí lo chicaneaban (lo increpaban verbalmente): 
Entrevistador: ¿con qué te chicaneaban?

A: y con... cosas... decían "¿qué hacías ahí? ¿Sos puto?" y ¿qué les vas a decir? ¿Sí, soy puto? Entonces decías, "no... fui a buscar un amigo... no, yo no tengo nada que ver..." Porque te ponían en la libreta si eras homosexual. Te marcaban en la libreta [de Enrolamiento]. ${ }^{6}$ Quedabas marcado. Entonces quedabas ya con un coso rojo [un sello] ahí en la libreta como homosexual. Enfermo. Entonces era ¿viste? Feo. Entonces todo el mundo decía "no, no soy", "no, no sabía qué era", "no, fui a buscar a un amigo...". Un sello te marcaban, te ponían ahí que habías estado detenido en un bar por homosexual. Y eso. No usaban la palabra gay, ihomosexual! Y el artículo [del Código de Faltas $]^{7}$ tanto, que tiene que ver con las costumbres, con las buenas costumbres.

Cuando narraban apasionadamente los peligrosos encuentros con las fuerzas policiales los sujetos contaban cómo procuraban definir la situación frente a quienes representaban el "brazo armado" del estado. Para ello mostraban, como gran parte de la población civil, modales deferentes y actuaban una performance de obediencia y respeto frente al agente policial que exigía identificarse. Esa escena, más o menos cotidiana en

\footnotetext{
${ }^{6}$ La Libreta de Enrolamiento era el documento nacional de identificación con el cual contaban los ciudadanos argentinos masculinos, mientras que las mujeres disponían de Libreta Cívica. Este documento informaba sobre los datos filiales de la persona, el cumplimiento de los servicios de conscripción y era obligatorio para el ejercicio electoral. En 1968 fue reemplazado por el Documento Nacional de Identidad (Ley 17.671), quedando ambos registros en funcionamiento.

7 Según se indicó en la nota 4, en la Provincia de Córdoba estaba vigente un Código de Faltas que habilitaba la detención de varones homosexuales en función de diversos artículos. Algunos de sus apartados asociaban bajo un mismo título prostitución con la figura del homosexual o vicioso sexual. Otro conjunto de artículos sancionaba a aquellos individuos que realizaran escándalo público. Entre los agravantes se mencionaba a sujetos que profirieren gritos, hicieren ruidos o utilizaren otros medios capaces, conforme a las circunstancias, de causar escándalo o molestias a terceros.
} 
aquellos años, se transformaba ante la voz de mando acusatoria o la pregunta infamante: iusted es homosexual! ¿Sos puto, vos?

Frente a este tipo de interpelación policial en la vía pública era frecuente negar a muerte, es decir, aún a riesgo de la propia vida, la acusación de homosexualidad. Para disimular la pertenencia a determinadas redes de relaciones, el propio deseo, afectos, intereses y motivaciones, algunos entrevistados buscaban ajustar la situación a su favor mediante la desmentida. Esa acción verbal se acompañaba de la organización de la información que los sujetos comunicaban con el objetivo de producir una performance concordante con la negación. Al realizar esa actuación, los sujetos recurrían a sus habilidades dramáticas para construir una apariencia que fuera capaz de ocultar el sí mismo. Poses corporales, tonos de voz, y gestualidades debían ser capaces de sostener la negación de la propia homosexualidad y proyectar una masculinidad heteronormada.

Para desprenderse del "estigma" homosexual, los entrevistados preparaban historias más o menos creíbles y repetían, insistentemente, yo no soy, yo no soy. En las escenas de peligro que se configuraban en la calle, los sujetos evitaban nombrarse o ser nombrados con términos como puto $\mathrm{u}$ homosexual. La negación de sí, el ocultamiento y el perfeccionamiento en la mímesis de las poéticas hegemónicas de la masculinidad eran tácticas centrales a la hora de interactuar con los agentes policiales.

El diferencial de poder a favor de los agentes estatales, capaces de atentar contra la vida de los ciudadanos, limitó la performance de Héctor que, pese a sus esfuerzos, naufragó. Acosado y separado de su compañero, Jorge consintió, en el sentido de "acatar una resolución judicial o administrativa sin interponer contra ella los recursos disponibles", y se hizo

8 Esos enunciados, y las condiciones que regulaban su fuerza performativa, merecerían ser analizados en relación con el mandato en vigor en las fuerzas armadas norteamericanas de "no preguntar y no decir" sobre la condición homosexual que problematiza Judith Butler (2004). 
homosexual. En un contexto de peligro y subalternidad, los amigos encarnaron líneas de acción opuestas y no lograron coordinar su actuación. La contradicción se hizo evidente, prueba suficiente para que ambos acabaran detenidos en la Jefatura de Policía de la Provincia de Córdoba.

Con el objetivo de evitar esos fracasos y sus temidas consecuencias, los sujetos se entrenaban en la construcción de una actuación que no resultara sospechosa. Construían performances de género para que no se note; hacían acuerdos y establecían guiones precisos con los amigos para evitar la disonancia en la ejecución. Algunos entrevistados recordaban cómo ensayaban, por las dudas que la policía los interceptara, un mismo relato cuya coherencia funcionaría como prueba de verdad. ${ }^{9}$

Esteban, de 58 años, relató durante la entrevista que realizamos una noche de 2013, cómo fue interpelado por un policía en una plaza céntrica de la ciudad capital de la provincia de Córdoba. En esta situación, había ensayadouna historia que suponía efectiva para los efectos defensivos que buscaba: "Yo ya me había armado mentalmente una historia, que iba a llamar a un juzgado por teléfono, haciéndome el que yo trabajaba en un juzgado. Toda esa historia tenía preparada". Esteban anticipaba la "escena de peligro". Organizaba, en soledad, un relato que pudiera amedrentar a los agentes estatales y evitara una posible detención. La táctica empleada no suponía la negación explícita de la homosexualidad; se apelaba a la actuación de una historia que invirtiera las jerarquías sociales. Ernesto pretendía demostrar un supuesto capital social, que no poseía, mediante una actuación que comunicara su pertenencia a redes de relaciones inmersas en

9 Mariana Tello Weiss (2012) analiza memorias de la "lucha armada" durante la década de 1970 en Argentina. La autora describe cómo esta forma de participación política modificaba los estilos de vida de quienes militaban. La actividad clandestina de la militancia suponía no sólo un lenguaje paralelo sino también un cambio en torno a la noción de persona, materializado en el cambio del nombre propio. Los entrevistados de la autora también inventaban historias (el minuto) que les servían como coartada en caso de ser sorprendidos por las fuerzas de seguridad en alguna cita o acción política. 
otros poderes, el judicial en este caso. Sujetos como el entrevistado procuraban construirse como superiores $y$, en una actitud desafiante, buscaban minar la autoridad policial al mostrarle su posición subordinada a otros poderes y autoridades estatales.

Si no se lograba evitar el arresto, los sujetos intentaban minimizar los riesgos y su estadía en la comisaría. Durante una de las entrevistas que realizamos con Rodrigo (61 años), recordó una noche que fue detenido:

Entonces en ese momento me acuerdo que yo estaba sentado con otro [en la celda], que yo lo conocía (...) y me dice "ni se te ocurra decir que me conocés". Me dice: "ni se te ocurra. Yo te voy a negar total, eh. Así que no digas que me conocés". Bueno. Y veo unos travestis que los traían. Yo no sabía dónde meterme porque me conocían, entonces di vuelta la cara y menos mal que los travestis no se dieron vuelta.

La táctica, en esta escena, consistía, una vez más, en negar vinculaciones que podían resultar comprometedoras. En el calabozo, se daba una cadena de reservas de información (ni se te ocurra decir que me conocés u ocultar la cara para no ser reconocido), negaciones y prácticas de evitación (Goffman, 1970) que desagregaban las redes de relaciones que daban forma al llamado "ambiente" (Sívori, 2005). Bajo sospecha, los sujetos procuraban no interactuar con aquellos que podían hacer saber una información que ellos debían guardar para sí como una táctica para minimizar riesgos. En la promiscuidad y hacinamiento del calabozo, los vínculos se desarticulaban cuando los detenidos se daban vuelta la cara. Esas performances de desconocimiento, según cuenta Ernesto, estaban organizadas de acuerdo a ciertas jerarquías que subordinaban aún más a las travestis, las únicas que "no se dieron vuelta". Los perseguidos por los agentes de la policía provincial también rehusaban su mirada y evitaban ser interpelados por ellas. 
Los relatos que nos confiaron los entrevistados también permiten observar algunas de las formas de actuación de los agentes policiales durante esos años. Sus primeras acciones eran detener la marcha de uno o varios transeúntes, interpelar a los entrevistados y exigirles la presentación de sus respectivos Documentos Nacionales de Identidad, facultad que tenían legalmente concedida. Con esas intervenciones inauguraban unas "escenas de peligro" que resultaban aún más riesgosas cuando los cuerpos policiales no se identificaban a partir del uso de uniformes reglamentarios. Según recordaba Héctor, muchas veces, eran tipos de civil..$^{10}$

Esa escena continuaba con el acoso verbal a ciertos paseantes, a quienes predicaban a partir del uso de categorías estigmatizantes y acusaban de ser aquello que no debían ser. Frente a ese panorama, los entrevistados intentaban no ser confundidos con un homosexual y para ello insistían maníacamente en la negación de su homosexualidad, en la búsqueda de la excelencia en la mímesis de un varón heterosexual, en la construcción de relatos creíbles que confirmaran la veracidad de su actuación y en la inversión de las jerarquías. Conocedores de estas tácticas, los policías buscaban minar su efectividad y para ello insistían en la acusación y separaban a los amigos para desmantelar los "equipos de actuación" (Goffman, 1971).

Algunas noches la escena concluía rápidamente, el peligro se evaporaba y los entrevistados continuaban su tránsito por la ciudad. Pero, en otras, la suerte no los acompañó y sus peores fantasías se hicieron realidad. Como Rodrigo, acabaron en un calabozo donde fueron ignorados e ignoraron a quienes conocían del "ambiente". A otros, les podían sellar el documento de identidad que luego, cuando se lo volvieran a exigir, los delataría

${ }^{10}$ Con este término el entrevistado se refiere a la vestimenta de los agentes policiales, que no llevaban el uniforme de trabajo sino ropa casual. Por medio de esa táctica, los policías minimizaban las posibilidades de ser reconocidos como pertenecientes a dicha organización y procuraban volver más efectivas sus tareas de control y represión. 
de modo tal que ninguna de las tácticas conocidas resultaban útiles. Como parte de un círculo maldito, esos sujetos acababan, una y otra vez, en la cárcel. "Tres veces. Tres veces en un día me llevaron preso" recordaba, con dolor pero no sin cierto orgullo, un entrevistado.

\section{Me saqué la peluca y me empecé a cambiar}

Con la asunción de los gobernantes electos democráticamente, a finales de 1983, el peligro de las calles y el encuentro desafortunado con las fuerzas policiales no desapareció para homosexuales y travestis. Por el contrario, las razias se hicieron más frecuentes y las "escenas de peligro" continuaron reproduciéndose: después la cuestión se pone más represiva, recuerda un entrevistado que sufrió diecisiete detenciones. Más allá del restablecimiento de un orden constitucional existían prácticas y sujetos que, como bien sabían nuestros interlocutores, continuaban en estado de excepción o de sitio (Benjamin, 1995). Sujetos entrevistados coinciden en afirmar que en la democracia siguió la policía reprimiendo, siguieron haciendo razias hasta, al menos, inicios de la década de $1990 .{ }^{11}$ Una entrevistada contaba cómo, durante la época de Angeloz, te tenían entre ojos porque eras travesti y te llevaban igual. Frente a esa situación, los sujetos buscaban llegar a un arreglo para ser liberados. El acuerdo extorsivo suponía el pago de una coima y/o el consentimiento del abuso sexual: te obligaban a tener sexo oral y te soltaban, según recordaba Débora, de 51 años. Durante el momento histórico en cuestión, que algunos nombraron como la época en que un travesti no podía andar por la calle o la época que mataban a travestis, se intensificó el hostigamiento de ese sector de la población. Distintos testimonios sostienen que hubo un recrudecimiento de las prácticas represivas hacia los varones

\footnotetext{
${ }^{11}$ Cabe señalar que la fecha de finalización de esas prácticas represivas variaba entre los distintos entrevistados e incluso en las palabras de un mismo sujeto. Varios afirmaron que esas intervenciones policiales continuaban al momento de la entrevista.
} 
homosexuales y un selectivo mayor maltrato institucional hacia las personas travestis.

Al recordar esos años, Héctor encadenaba diversas "escenas de peligro" cuando pasaba de la narración de las situaciones protagonizadas por sus amistades a las suyas propias. Así, nos contó aquella misma tarde de primavera que nos reunimos en su casa:

En la época de Alfonsín, yo una vez voy en el autoy la veo a la Fabiana [un amigo que se travestía] caminando por la Colón arriba, por la General Paz [calles céntricas de la ciudad de Córdoba]. La veo caminando con una pollerita por acá [indica el escaso largo de la pollera] y con la peluca. Y digo, ipero ésta está loca! iQué enferma! Andar así por la calle... qué riesgo. Y se iba para su casa.

Héctor calificó como loca y enferma a su amiga no tanto por haber construido una apariencia de mujer sino porque desplegaba esa performance en pleno centro de la ciudad. Vestirse con ropas femeninas, maquillarse, usar peluca eran prácticas que debían reservarse para un público determinado y mantenerse alejadas de la mirada policial. La táctica de los sujetos pasaba por la segregación de audiencias y la reserva de espacios donde esas performances pudieran darse de manera segura. Fabiana, con su corta minifalda, abandonó ese guión y optó por la profanación de las convenciones sobre las formas de presentación que se consideraban apropiadas y seguras para caminar por las calles céntricas. Su acción la exponía a graves peligros y a riesgos ya conocidos desde los tiempos dictatoriales.

Luego, Héctor continuó:

Vos sabés que una vez, te digo por contarte, salíamos en el auto. Vestidas de mujer. O sea, yo salía del boliche, me subí al auto, vestida de mujer e îbamos a la casa de la Fabiana. En este caso estaba también otra amiga, la Adriana. Entonces se nos rompió el auto. Pero íbamos de mina. Íbamos volando y rezando que no nos parara la cana 
[policía]. Se nos rompió el auto, o se quedó sin nafta. No sé, algo le pasó ¿vos sabés lo que hice? Ellas se me mataban de risa. Pero yo agarré, me saqué la peluca y me empecé a cambiar. Y con saliva me sacaba el maquillaje, porque ni crema tenía, del cagazo que me parara la policía. Me llevaban. Me llevaban.

Nuevamente, y como en los tiempos de la dictadura, Héctor sufrió cagazo frente a una posible interpelación y posterior detención policial. Dentro de la máquina que los transportaba por la ciudad, él y Adriana se sentían a salvo. El auto, la casa y el boliche eran escenarios donde podía subvertirse dramáticamente el orden que imponía la correspondencia entre sexo anatómico y performances de género. Esos espacios, a diferencia de la calle, menos expuestos a la mirada policial, resultaban más seguros.

La situación mutó súbitamente cuando un imprevisto mecánico detuvo la marcha del vehículo que servía de refugio. Con el accidente, una presentación de sí destinada a una audiencia exclusiva podía hacerse pública y devenir peligrosa, loca, para los sujetos que la sostenían. En caso de toparse con la policía, Héctor tampoco conseguiría esta vez convencer a las autoridades de que no era homosexual. Pero, si la primera vez fracasó por culpa de Jorge ahora sería él mismo el agente de su propia derrota ¿Cómo habría de sostener la negación con peluca y maquillaje?

El imprevisto demandó una rápida respuesta. Héctor desmontó, un tanto torpemente, la presentación de sí que había producido para otra actuación. Él guió su actividad anticipando la posible amenaza. Sus acciones desesperadas y condenadas al fracaso, como intentar retirar el maquillaje con saliva, despertaron la risa del resto de los sujetos. Por medio de ese gesto, los compañeros de Héctor -en tanto miembros de un mismo equipole hicieron saber que comprendían los peligros a los cuales quedaban expuestos. A través de la risa, y con tono de broma que la memoria y los repetidos relatos se encargarían de transformar en un recuerdo posible de ser contado, ellos también le hacían 
saber que, aunque rechazaban su decisión, no estaban en desacuerdo con su accionar.

Los relatos nos muestran cómo a pesar del "destape" y la liberalización de las costumbres, y de los discursos sobre derechos humanos y respeto a las libertades individuales que circulaban en la época de Alfonsín, los entrevistados se sabían bajo estado de sitio. Ellos experimentaban su existencia como precaria, especialmente en la calle. En ese escenario, algunos, como Héctor, recluían sus prácticas homosexuales en espacios reservados compartidos con iguales y ante un posible peligro retomaban las tácticas de negación ya conocidas. Como él mismo sabía, y las amigas se encargaron de recordarle a partir de la risa compartida, esas acciones serían ineficaces y lo llevarían nuevamente al calabozo. Sin embargo, él insistía.

En lugar de la negación de la homosexualidad, asociada con los tiempos dictatoriales y, según los entrevistados, bastante poco efectiva, algunos sujetos ensayaron otras tácticas. Con la llegada de la democracia, prácticas como el travestismo homosexual y el "loqueo" (Perlongher, 1993) ganaron el espacio público donde se exponían y afrentaban las fuerzas policiales. Como Fabiana, otros sujetos optaron por el montaje y la exhibición descarada de sí en plena calle. Ella, loca y enferma, conocía y desconocía simultáneamente las normas hegemónicas tanto como las tácticas subalternas. Nuevas "escenas de peligro" se organizaron a partir de esas formas escandalosas de afirmación de sí y desafío de los poderes instituidos.

\section{Que vengan porque voy a romper todo}

Las escenas siguientes ocurrieron en el tiempo histórico de la democracia recuperada en el año 1983 y tienen como protagonista a un joven Darío, de 50 años al momento de la entrevista en 2011.

Después en la democracia siguió la policía reprimiendo. Siguieron haciendo razias. Se llamaban razias; así que 
levantaban a todo el mundo. Se siguió reprimiendo pero ya era un poco distinto porque... creo que por nosotros también empezamos a reaccionar y hacíamos quilombo. Y también no le convenía a la policía tener estos, a ver, que nos van a incendiar la comisaría.

Según nos hace saber el entrevistado, bajo el nuevo régimen democrático las razias continuaban al igual que los interrogatorios, el maltrato físico y verbal, las detenciones y el hacinamiento experimentado en los calabozos de las seccionales de policía donde eran recluidos en los años dictatoriales. Pero, a diferencia de lo que hemos descripto hasta aquí, algunos sujetos implementaron otras formas de definir la situación en los encuentros con las fuerzas policiales. Esas nuevas "escenas de peligro" emergieron tanto por el propio hartazgo de los sujetos ante la continuidad del hostigamiento policial como por el nuevo tiempo político donde aparecían con fuerza los discursos y acciones enmarcadas en el horizonte de los derechos humanos, se cuestionaba la moral "occidental y cristiana", pacata e hipócrita, que sostenía la última dictadura y se producía una renovación del repertorio de guiones y prácticas eróticas asociada con "la primavera alfonsinista".

Cuando aparece la democracia, ahí entonces va a haber como un envalentonamiento. Que de eso siempre me acuerdo. Había un cana [policía] que me dice: "ehhh ¿qué hacés acá? Bueno entonces dame plata...". Me saca el documento. Yo me acuerdo que me saqué ya porque estaba podrido que me metieran en cana [calabozo]. Entonces le digo: "Bueno dale. Que vengan. Llamá al patrullero, llamá a los patrulleros que vengan porque voy a romper todo. Te voy a matar a vos, voy a matar a todos. Me van a tener que matar. Voy a hacer un quilombo". Y lo dije de una manera que se ve que el tipo se asustó y me dio las cosas de vuelta. Y me dice: "Bueno chau flaco. Chau, chau". Porque claro, estaban acostumbrados a la cosa más dócil- pasiva, donde vos pagabas, o tratabas de arreglar para zafar de esa situación ¿No? La policía re jodida. Te 
pegaban. Te basureaban. Te trataban para el culo. Te insultaban. Era como que eras medio lo peor...

El envalentonamiento del que nos habló Darío durante la entrevista consistía en acabar con la construcción de una performance de sí que buscara confirmar una apariencia heteronormativa exigida y esperada por los agentes policiales. Durante la interacción con el policía acosador, el entrevistado rechazó el repertorio de acciones convencionalizado propias de las "escenas de peligro" anteriores donde unos abusaban y los otros se sometían dada la correlación de fuerzas abismalmente adversa en el marco del Terrorismo de Estado. En democracia, Darío se sacó ante la figura del policía cuya nueva fachada social institucionalizada exigía el respeto a los derechos humanos pero que actuaba abusivamente.

Por medio del escándalo, Darío actuaba tanto de forma opuesta a la proyectada oficialmente como a la que estaban acostumbrados muchos homosexuales que procuraban ser discretos. ${ }^{12}$ El entrevistado no se identificaba con el status social de ser medio lo peor que el policía le asignaba, y que guiaba las prácticas cotidianas de maltrato, ni accionaba las tácticas de negación habituales entre otros homosexuales. Por medio de un desafío abierto y directo, Darío transgredió los límites acostumbrados que implicaba el trato con los agentes policiales y construyó una nueva "escena de peligro" al hacer quilombo. ${ }^{13}$ Con su accionar inesperado, por fuera del guión preestablecido, él se colocó en esa escena del lado del loco, del anormal, del peligroso. A los gritos, rechazó abiertamente el acto de deferencia y sumisión que exigía la intervención policial y con su

\footnotetext{
${ }^{12}$ Una categoría de uso frecuente en la época era la de loca escándalo. Con ese término se describía a un varón, más o menos afeminado, cuya homosexualidad era ostensible y no podía ser disimulada. En el polo opuesto se encontraba la loca discreta u onda nada que ver que podía reclamar alguna verosimilitud en su performance de una masculinidad heteronormada.

${ }^{13}$ En el castellano que se habla en el Cono Sur el término quilombo refiere a un prostíbulo o, como en este caso, a lío, barullo, gresca, desorden.
} 
performance consiguió asustar al policía que desistió de su acción autoritaria.

En otro momento de la entrevista, Darío nos invitó a imaginar lo que sucedió una noche en la que un grupo de amigos acabaron presos en la comisaría:

IImaginate! Eran treinta en una celda. Un escándalo. Querían salir a bailar y de pronto a las tres de la mañana estaban todos en la comisaría. Por eso te digo, de ser cosas densas, después como que la policía tampoco pudo controlar más eso. Entonces lo dejaron de hacer también. Se les iba de las manos por el quilombo que armaban. Lo peligroso era cuando te llevaban a vos solo. O a dos. Eso era lo jodido. Que te subían a un auto y vos no sabías a dónde ibas. Eso era lo jodido...

Según pudimos saber, bajo las nuevas condiciones políticoinstitucionales democráticas y la continuidad $e$ intensificación de las razias, algunos homosexuales, especialmente jóvenes de camadas medias, comenzaron a ejercitar otras tácticas al enfrentarse con los agentes policiales. Cabe destacar que en esas escenas, los sujetos ponían a su favor la nueva valoración positiva de los jóvenes universitarios que se produjo durante el alfonsinismo (González, 2012). Antes que el sometimiento y la negación, sujetos como Darío comenzaron a cultivar diferentes maneras de intervención y de redefinición de las "escenas de peligro" que experimentaban. Con acciones desafiantes y bravías, por medio del quilombo que su condición juvenil le permitía hacer, esos sujetos procuraban modificar los desequilibrios de poder.

El escándalo fue la forma más importante que adquirió esa táctica en los primeros años de la recuperación democrática de la década de 1980. Gritos, amenazas públicas, gestos hiperbólicos, conformaron parte de la poética de los encuentros con la policía. Esas performances implicaban actuaciones más desobedientes, directas y expresivas cuyo objetivo era crear un momento de 
confusión e inestabilidad en las interacciones con los agentes de la policía.

El "comportamiento escandaloso" en la vía pública, en tanto motivo de detención según el Código de Faltas vigente en la época, se transformó en un recurso que algunos podían utilizar para defenderse del hostigamiento policial. En una especie de "rellenamiento estratégico" (Foucault, 1984), Darío y otros jóvenes se apropiaron y actuaron el rol asignado a las locas y de los saberes que esos sujetos construyeron para, en un contexto donde se imponía una etiqueta de respeto a los derechos humanos, enfrentar a los agentes policiales que no acataban la nueva era constitucional. Esas intervenciones, como bien sabían nuestros entrevistados, encontraban sus límites y el envalentonamiento resultaba menos peligroso y más efectivo cuando se actuaba de manera grupal.

\section{Reflexiones finales}

Los generosos relatos de nuestros interlocutores nos permitieron observar, para la ciudad de Córdoba durante la década de 1980 y en una escala microsociológica, cómo se transformaron las interacciones entre sujetos que ocupaban una peligrosa posición subordinada, en función de sus prácticas eróticas y modos de hacer género, y quienes se encargaban de reprimirlos en el espacio de la calle.

En un primer momento, durante el Terrorismo de Estado, cuando los diferenciales de poder estaban fuertemente establecidos, los entrevistados se especializaron en la administración del secreto (a voces) de su homosexualidad. Esa gestión de sí suponía la segregación de audiencias, la integración en "el ambiente", la negación pública de sus deseos eróticos y, en caso de ser detenidos, el desconocimiento o dar vuelta la cara a los pares y a las travestis. Otros sujetos, como Esteban, antes que negar su homosexualidad buscaban invertir las jerarquías sociales que ordenaban la "escena de peligro". Con una actitud desafiante, que podía llegar al escándalo, ellos montaban una performance 
que exaltaba sus capitales sociales y mediante la cual procuraban socavar la autoridad del agente policial al mostrarle su posición subordinada.

Ese cultivo de la capacidad para anticipar situaciones riesgosas y el ensayo de performances que reforzaran la negación de su homosexualidad o les permitieran construir una imagen aumentada de sí, formaban parte de las prácticas que, hechas habitus, permitieron a ciertos sujetos enfrentar condiciones adversas para su reproducción social y erótica durante la última dictadura.

Las formas de interacción entre los entrevistados y los agentes de la policía se modificaron con el correr de la década. Bajo el orden democrático que se instituyó a finales de 1983, las detenciones callejeras y las persecuciones policiales a varones homosexuales y travestis comenzaron a asumir mayor notoriedad en un contexto de creciente organización política, lucha por derechos, visibilización de la homosexualidad en la escena pública y la apertura de espacios propuestos como lugares gay. Aprovechando las nuevas condiciones políticas, especialmente en relación con los discursos sobre los Derechos Humanos y las luchas por el reconocimiento de los homosexuales como sujetos de derecho, algunos entrevistados se rebelaron y se revelaron. ${ }^{14}$ Por aquellos años, una nueva política basada en el visibilización de cierto sujeto homosexual comenzaba a emerger entre una nueva generación de varones homosexuales de camadas medias, como Darío, que comenzaban a decirse gays. Al mismo tiempo, comenzaron a cuestionarse los discursos religiosos, médicos, psicoanalíticos que patologizaban la homosexualidad. ${ }^{15}$

\footnotetext{
${ }^{14}$ Esta nueva táctica coagulará en la formación de la Coordinadora de Grupos Gays en 1983 y la Comunidad Homosexual Argentina en 1984 (Jáuregui, 1987).

${ }^{15}$ Esa visibilización y despatologización de una homosexualidad gay y masculina puede observarse en la prensa y la producción cinematográfica. En 1985 Siete Días, una revista semanal de gran circulación, publicó en su tapa la foto de dos varones abrazados (Raúl Soria y Carlos Jáuregui) con el título: "Investigación especial: El riesgo de ser homosexual en la Argentina". Ese mismo año se estrenó "Adiós Roberto" el primer film nacional en tener como protagonistas principales
} 
En las "escenas de peligro" que se producían en la calle cuando se encontraban con la policía, esos sujetos no trataban de negar la propia homosexualidad. Por el contario, ahora se desafiaban abiertamente los ejercicios de poder policial. En esas escenas ya no se respetaban los "buenos modales" ni se ocultaba la propia homosexualidad. Frente a la continuidad de las acciones policiales, las reacciones de los entrevistados, especialmente los más jóvenes, habían mudado. Envalentonados, ellos buscaron quebrantar, mediante el escándalo, la autoridad de la policía y disminuir los diferenciales de poder entre los protagonistas de estas escenas. Su acción, aunque novedosa, especialmente para los policías que, como contó Darío, terminaban abandonando la escena, recuperaba al escándalo como forma de protección y lucha frente a la agresión homo-transfóbica, utilizadas por travestis y locas desde décadas anteriores (Blázquez y Lugones, 2014; Juárez, 2010). ${ }^{16}$

Durante los años de la última dictadura o cuando se estaba en soledad predominaba la negación. Ya en los tiempos democráticos, y especialmente en compañía de otros, se desplegaba la hipervisibilización tumultuosa y ruidosa. Esa discontinuidad de los modos de actuar las "escenas de peligro"

a una pareja de varones homosexuales y donde se presentan de manera caricaturesca los discursos homofóbicos (Blázquez, 2015). Las lesbianas encontraron un espacio para su visibilización en el mundo del rock nacional a partir de la producción de artistas como Sandra Mihanovich, Marilina Ross y Celeste Carballo. Paralelamente, las organizaciones gays comenzaron a politizar la homosexualidad y a presentar sus reivindicaciones en la agenda política, proceso que se vio motorizado por el surgimiento y expansión de la epidemia de HIV-Sida.

${ }^{16}$ Pese a que travestis y locas ya implementaban la táctica del escándalo desde al menos- la década de 1970, lo hacían en espacios sociales donde las interacciones se encontraban mediadas por otro tipo de intercambios como bienes o servicios sexuales. El escándalo rara vez era puesto en acto en el escenario de la calle y, de ser así, las acciones difícilmente tenían resultados favorables para los sujetos entrevistados. Asimismo, según nos contó Darío, esta práctica sería retomado en los años noventa, en el contexto de las movilizaciones que reclamaban la entrega gratuita de medicamentos para enfermos de Sida. 
por parte de varones homosexuales forma parte de un proceso social mayor donde destacamos los cambios en las formas político-institucionales y los discursos sobre los Derechos Humanos (Bellucci, 2010); las transformaciones en la moral sexual (Blázquez y Lugones, 2014) y en la valoración social de los jóvenes (González, 2012); la emergencia de nuevas generaciones y formas de experimentar la homosexualidad (Meccia, 2011).

Además de dar cuenta de la continuidad en los modos de intervención policial, la actualización del escándalo como táctica de enfrentamiento con los efectivos policiales nos advierte sobre la existencia de redes donde se forjaba una "tradición de los oprimidos". Ante las abusivas interpelaciones policiales, los sujetos se defendían a partir de saberes y destrezas, de tácticas, que se transmitían a medida que participaban y se integraban en determinados circuitos de conocidos, amantes y amigos. En el "ambiente", heterogéneo en términos generacionales y en cuya formación fueron de gran importancia las fiestas, los bares y discotecas (Reches, 2014) tanto como los encuentros callejeros, las locas de mayor edad pasaban sus saberes a los gays más jóvenes. Ellos, valiéndose de su condición juvenil y de sus performances de género masculinas, enfrentaban a los agentes policiales y modificaban a su favor los diferenciales de poder. ${ }^{17}$

En la calle, cuerpo a cuerpo, esos sujetos transformaban, en el nuevo escenario democrático, su condición subalterna al mismo tiempo que definían como legítima una nueva forma de ser un varón homosexual que excluía prácticas "escandalosas" como el travestismo homosexual y el "loqueo" de Fabiana y Héctor. Informadas por los saberes de locas y travestis, las acciones de los gays pronto acabarían por excluirlos y censurarlos, mostrándonos, una vez más, cómo "el estado de excepción en que vivimos es la regla" (Benjamin, 1995:53).

\footnotetext{
${ }^{17}$ Otras veces y a partir de esos mismos recursos que les permitían mantenerse con mayor seguridad dentro del armario que las locas, diversos varones gays cultivaron formas menos desafiantes y más predispuestas a llegar a un arreglo, generalmente mediado por una coima, que les permitiera evitar la detención y la marca en el documento de identidad.
} 


\section{Referencias bibliográficas}

BAzÁn, Osvaldo. Historia de la homosexualidad en la Argentina: de la Conquista de América al siglo XXI. Buenos Aires, Marea, 2006.

BElluCCI, Mabel. Orgullo: Carlos Jáuregui, una biografía política. Buenos Aires, Emecé, 2010.

BENJAMIN, Walter. Sobre el concepto de Historia. In: BENJAMIN, Walter. La dialéctica en suspenso. Fragmentos sobre la Historia. Santiago de Chile, ACIS-LOM, 1995, p.53.

BLÁZQUEZ, Gustavo. Cine, tecnologías del erotismo y homosexualidades masculinas en Argentina. Estudios, Córdoba, 2015, n 34, pp.273287.

BLÁZqueZ, Gustavo y LugONES, María Gabriela. "Cositas fuera de lugar" "Miradas oblicuas en y sobre una noche cordobesa de inicios de los ochenta. In: BARRANCOS, Dora; GuY, Donna; VALOBRA, Adriana (eds.) Moralidad y comportamientos sexuales (Argentina, 1880-2011). Buenos Aires, Biblos, 2014, pp.180-203.

BRUNO, María Sol. Al ritmo de la música. De noche y de día, trayectorias y devenires juveniles en la Córdoba de los ochenta. Question, La Plata, 2014, vol. 1, n 44, pp.240-253.

BUTLER, Judith. Lenguaje, poder e identidad. Madrid, Síntesis, 2004.

CAlveiro, Pilar. Política y/o violencia: una aproximación a la guerrilla de los años 70. Buenos Aires, Norma, 2005.

CAVArozZi, Marcelo. Autoritarismo y democracia. Buenos Aires, Eudeba, 2006.

Foucault, Michel. Saber y Verdad. Madrid, Ediciones de la Piqueta, 1984.

GLUCKMAN, Max. Análisis de una situación social en Zululandia moderna. bRiCoLaGe, México, 2003 [1940], vol. 1, nº 1, pp.33-49.

Goffman, Erving. Ritual de la interacción. Buenos Aires, Tiempo Contemporáneo, 1970.

. La presentación de la persona en la vida cotidiana. Buenos Aires, Amorrortu, 1971. 
GONZÁLEZ, Alejandra Soledad. "Juventudes" (in)visibilizadas en la última dictadura. Estetización de la política y politización de la estética en performances oficiales de Córdoba (1980-1983). Tesis de Doctorado, Historia, UNC, 2012.

JÁUREGUI, Carlos Luis. La homosexualidad en la Argentina. Buenos Aires, Tarso, 1987.

JuÁREZ, Marcelo Oscar. Marcela. La Pochocha. Córdoba, s/e, 2010.

LONGONI, Ana. Activismo teatral durante la última dictadura argentina: Apuntes sobre el Taller de Investigaciones Teatrales. Philadelphia, Art Journal, 2014, vol. 73, n 2, pp.90-115.

LUCENA, Daniela. Estéticas y políticas festivas en Argentina durante la última dictadura militar y los años 80. Córdoba, Estudios Avanzados, 2013, n 18, pp.35-46.

MECCIA, Ernesto. La cuestión gay: un estudio sociológico. Buenos Aires, Gran Aldea, 2006.

. Los últimos homosexuales. Sociología de la homosexualidad y la gaycidad. Buenos Aires, Gran Aldea, 2011.

. El tiempo no para. Los últimos homosexuales cuentan la historia. Buenos Aires, Eudeba, 2016.

PECHENY, Mario. Parece que no fue ayer: el legado político de la Ley de Divorcio en perspectiva de derechos sexuales. In: GARGARELLA, R., Murillo, M.V.; PeChenY,M. (comps.) Discutir Alfonsin. Buenos Aires, Siglo XXI, 2010, pp.85-113.

PERLONGHER, Néstor. La prostitución masculina. Buenos Aires, Ediciones de la Urraca, 1993.

. Prosa plebeya: ensayos, 1980-1992. Buenos Aires, Colihue, 1997.

QuirogA, Hugo. El tiempo del "Proceso". Conflictos y coincidencias entre políticos y militares. Rosario, Homo Sapiens,2004.

RAPISARDI, Flavio; ModARELli, Alejandro. Fiestas, baños y exilios: los gays porteños en la última dictadura. Buenos Aires, Sudamericana, 2001. 
ReChes PeRESSOTTI, Ana Laura. Prácticas de sociabilidad festiva de varones homosexuales a inicios de la década de 1980 en la ciudad de Córdoba. La Plata, Question, 2014, vol. 1, n42, pp.376-391.

RomeroLuis Alberto.Breve Historia Contemporánea de Argentina. Buenos Aires, Fondo de Cultura Económica, 2001.

SCHECHNER, Richard. Performance: teoría y prácticas interculturales. Buenos Aires, Libros del Rojas, 2000.

Servetto, Alicia;GonZÁlez, Alejandra Soledad. La Historia Reciente Argentina desde los sectores dirigentes. Un análisis desde la Historia Oral a un candidato presidencial de la transición democrática de la década de 1980: Eduardo César Angeloz. Córdoba, Estudios Avanzados, 2014, n²1, pp.47-68.

SIVORI, Horacio Federico. "El cana como entendido. 'El estado' y la cultura íntima de los varones homosexuales en Argentina", 19831996. Puerto Rico, Revista Jurídica de la UIPR, 2003, vol. 38, pp.225-453.

- Locas, chongos y gays. Sociabilidad homosexual masculina durante la década de 1990. Buenos Aires, Antropofagia, 2005.

TAYLOR, Diana. Introducción: performance, teoría y práctica. In: TAYLOR, Diana; FUENTES, Marcela A., Estudios avanzados de performance. México, FCE, 2011, pp.7-30.

TELlo WeISS, Mariana Eva. La vida en fuego: un análisis antropológico sobre la memoria de la "lucha armada" en los 70 en Argentina. Tesis de Doctorado, Antropología, Universidad Autónoma de Madrid, 2012.

TURNER, Victor;BRUNER, Edward. TheAnthropology of Experience. Illinois, University of Illinois Press, 1986. 